\title{
Processo de Conhecimento e Liberdade ${ }^{(*)}$
}

\author{
Cândido R. Dinamarco \\ Professor de Direito Processual da \\ Faculdade de Direito da USP
}

\begin{abstract}
SUMARIO: 1. Processo, liberdade e advogado - 2. Primazia cronológica 3. Estado e poder - 4. O exercício do poder pelo Estado contemporâneo - 5. Jurisdição, ação, defesa e processo - 6. O conteúdo da jurisdição 7. Cognição e execução - 8. A liberdade através do processo de conhecimento - 9. Escopo específico do processo de conhecimento - 10. Processo de conhecimento e certeza - 11. Objeto do conhecimento -12 . Conhecer 13. Conhecimento no processo de execução - 14. Conhecimento no processo cautelar - 15. Conhecimento, publicidade, motivação, justiça e liberdade.
\end{abstract}

\section{1 - Processo, liberdade e advogado}

Convidado a discorrer sobre o processo de conhecimento perante um auditório de advogados reunidos por iniciativa de sua Ordem, senti que a mais elevada maneira de homenageá-los seria o enquadramento do tema no contexto democrático da defesa da liberdade. Os advogados são perenes defensores da liberdade, em juízo ou fora dele. Foi advogado o tribuno Cícero, que soube defender o poeta Archia e, em nome das liberdades políticas de sua nação romana, soube também incriminar Catilina. Foram os advogados o último bastião da liberdade, no segmentos mais negros do longo período de obscurantismo do Estado autoritário brasileiro. $\mathrm{E}$ a ordem processual com que lidamos nós juízes e vós advogados e que por vocação é democrática, ao mesmo tempo constitui instrumento de luta pela liberdade e traz ela própria a marca da liberdade, no modo como os seus sujeitos são admitidos a participar.

Falando em processo e em liberdade, estarei falando em advogado e em Ordem dos Advogados do Brasil.

\section{2 - Primazia cronológica}

Todo Estado incipiente tem dificuldades para impor-se sobre o individualismo dos seus membros. Assim foi o romano, fonte das nossas instituições jurídicas. $\mathrm{E}$ isso concorre para que possamos compreender a prioridade cronológica da jurisdição ante a legislação, entre as ins-

(*) Conferência proferida em ciclo de estudos de iniciativa da Ordem dos Advogados do Brasil, Seção de São Paulo, a 18 de agosto de 1982 (Sala do Estudante, Largo de São Francisco). Texto redigido pelo autor, tomando por base o roteiro então seguido. Trabalho destinado em homenagem ao prof. Joaquim Canuto Mendes de Almeida. 
tituições políticas; e da cognição sobre a execução, entre as processuais.

Assim como as entidades supra-estatais de hoje, também o incipiente Estado romano não dispunha de suficiente poder sobre os indivíduos, para impor-lhes com segura imperatividade as disposições de uma legislação integral (a comparação vem de Calamandrei). A solução dos conflitos interindividuais por obra do Estado começou, por tanto, na fragmentariedade das decisões judiciais, ditadas para casos concretos isolados e sem a menor vocação à generalidade. O extremado culto à livre vontade das pessoas impedia uma ordem jurídica que se impusesse a todos e com caráter permanente. Fora dos limites do jus civile, foi mais fácil o exercício do poder através do pretor e dos seus editos: ele prometia «conceder ação» nos casos que especificava num rol (actio dabo) e em cada actio residia, indiretamente e de forma rudimentar, um direito subjetivo abstratamente instituído.

A jurisdição, naqueles primórdios, limitava-se ao judicium, ou seja, ao processo de conhecimento: daí, jurisdictio, ou seja, função e atividade voltadas a «dizer o direito». Tanto quanto os organismos internacionais hoje, o Estado romano sentia-se incapaz de impor-se imperativamente na execução, fazendo curvar-se o indivíduo em sua resistência. $\mathrm{O}$ próprio processo de conhecimento era feito mediante um contrato entre os litigantes, a litiscontestatio (não havia a inevitabilidade do poder estatal, como hoje, em que sequer se pode pensar no processo como contrato, sendo destituída de qualquer função ou significado a «litiscontestação»). A execução era feita de mão própria e somente autorizada pelo pretor romano, na actio judicati. A execução pelo Estado seria vista como indevida restrição à liberdade das pessoas.

Essa prioridade do processo de conhecimento sobre os demais e sobre a legislação estatal também é, por certo, fator de grande peso para o extraordinário desenvolvimento de sua teoria, muito à frente do estudo das demais espécies de processos.

\section{3 - Estado e poder}

O Estado é o mais qualificádo e respeitável pólo de poder na sociedade, se bem não seja o único. Tem-se por poder a capacidade de influir nas decisões alheias, ou capacidade de decidir por outrem («poder é também um mecanismo de transmissão de resultados de seleção e até mesmo de obras de seleção produzidas pela decisão»: Niklas Luhmann. Na Escola Superior de Guerra, ele é apresentado como: «meios de toda ordem, de que dispõe a nação para a busca do bem-comum» (aqui, já está presente uma alusão teleológica ao bem-comum da nação e tem-se em vista o poder nacional). É a «capacidade de mandar e ser obedecido». Estando a nação organizada em Estado, boa parte do seu poder é exercida por este, falando-se então em poder estatal. A noção de Estado, aliás, está intimamente ligada à de poder, mesmo porque sem este inexiste aquele. 
O Estado não dispõe de poderes, ou «Poderes», mas do poder. A sua capacidade de decidir e impor a decisão é uma só, ainda que aplicada no cumprimento de diversas funções e mediante formas diferentes. Sabe-se até que, no Estado contemporâneo, que é Estado social e pretenda ser «a providência do seu povo» (Manoel Gonçalves Ferreira Filho), a gama de funções assumidas por ele é muito maior que a do Estado liberal, que deixava fazer em vez de fazer ele próprio, crente de que o mundo assim caminharia por si próprio e sem a sua ajuda («lais sez faire, laissez passer et le monde va da lui-même»). Seja lá ou cá, não se pode ter por adequada a «separação de Poderes», ou a "harmonia de Poderes», de que se costuma falar desde os tempos de Montesquieu. Sendo único o poder estatal, o que se vê nas Constituições modernas é somente a divisão do exercício do poder pelos diversos organismos estatais: cada "Poder» é um organismo estatal, um conjunto de órgãos voltados precipuamente a determinadas atividades (daí, ser errado dizer que «o Poder Judiciário é exercido pelos seguintes órgãos»: Const., art. 112; ele é composto pelos órgãos que a Constituição indica).

\section{4 - O exercício do poder pelo Estado contemporâneo}

Havendo abandonado a teoria dos «fins limitados», o Estado contemporâneo é welfare State e vai muito além dos escopos de manter a ordem interna, a segurança externa e as relações internacionais) (Dalmo A. Dallari). Assumindo mais responsabilidades em decorrência dos sucessivos movimentos que o abriram à participação de número crescente de pessoas, situadas em estamentos sempre mais diferenciados (Revolução Francesa , revolução industrial, a expansão bombástica da população e dos meios de comunicação de massa, a universalização do voto), o Estado viu-se a braços com atividades muito mais numerosas e urgentes, crescendo com isso o Poder Executivo perante os demais (porque mais ágil e por isso capaz de atender com mais presteza às mutantes e emergentes necessidades da população).

Varia no tempo e lugar a fórmula do equilíbrio político entre o Executivo, assim necessariamente forte, e os demais «Poderes» do Estado. Onde esse fortalecimento funcional do Governo vai ao ponto e se põe em termos de significar afrouxamento das funções exercidas pelo Legislativo e Judiciário, a democracia periga. Sem um eficiente sistema de contenção, fiscalização e controle, o Executivo dá asa à sua natural tendência ao absolutismo. O poder é sedutor.

Ao Judiciário, que não dispõe da espada nem da bolsa e por isso depende em boa medida dos demais, resta sempre o respaldo da força que lhe é conferida pela confiabilidade. É do sentimento comum da nação a inseparabilidade entre as idéias de Estado-de-direito e a de um Judiciário suficientemente forte para conter a expansão dos demais «Poderes», especialmente do Executivo sendo sempre capaz de solucionad adequadamente os conflitos interindividuais, com imparcialidade. No estado-de-direito, os juízes e tribunais emitem comandos ao próprio Executivo e este os acata. 
No atual estágio do Estado social, com finalidades bastante amplas e muita responsabilidade assumida perante sua população, as funções instrumentais que ele exerce também se multiplicam. Traçando um quadro dessas funções, temos que elas consistem em:

a) traçar diretrizes da vida do próprio Estado e da sua nação, definindo os objetivos aos quais se endereçará o exercício do poder. Tais diretrizes estão expressas fundamentalmente na Carta Política e constituem o arcabouço central de toda a atividade estatal. Definem-se, mediante elas, as instituições políticas e o seu modo de ser e o modo como se harmonizam; traçam-se metas econômicas e estabelecem-se critérios para a coordenação da vida econômica da nação; opta-se por certos estilos de vida e de cultura, no planejamento psicossocial das instituições familiares, educacionais, religiosas; e finalmente estabelecem-se os critérios para a segurança, mediante as diretrizes relacionadas à espressão militar do poder;

b) ditar normas gerais e abstratas, em atividade normativa que se apóia no juízo valorativo da conduta das pessoas e nas formas de seu relacionamento em sociedade e com o próprio Estado, para com isso disciplinar a cooperação entre elas, com ou sem a participação deste, além de fixar critérios para a solução de conflitos de interesses;

c) revelar imperativamente, em casos concretos, a vontade virtualmente contida nessas normas gerais e abstratas, ou seja «aplicar» o direito a situações particularizadas na vida das pessoas e do próprio Estado (o que faz este toda vez que «julga», em face de litígios, seja ao dar resposta a requerimentos que lhe são dirigidos, ao coordenar seu pessoal, etc);

d) realizar os resultados práticos decorrentes dos preceitos concretos assim revelados.

Tais atividades do Estado, incluídas no tosco desenho acima, distribuem-se entre os seus três «Poderes», sem que qualquer deles tenha legitimamente a exclusividade de algumas delas. Não é o caso de desenhar também o quadro da distribuição das funções instrumentais do Estado, pelos seus diversos setores orgânicos («Poderes»). Importa somente colher o campo em que ele atua sub specie jurisdictionis, pois o discurso agora consiste no estudo de uma espécie de processo que se faz mediante o exercício da jurisdição.

\section{5 - Jurisdição, ação, defesa e processo}

Não me animo a buscar a essência da jurisdição, para distingui-la das demais funções do Estado. Não acho, mesmo, que ela seja ontologicamente diversa da legislação e administração, que constituem outras manifestações do poder, o qual é unitário e não comporta divisões ou alusão no plural. A jurisdição não me parece ser um poder, mas uma das suas possíveis expressões. O que a distingue é o conjunto das funções que o Estado exerce e que se costumam aglutinar no 
conceito de jurisdição. Chiovenda dá destaque à função jurídica, ao dizer que o escopo «do processo» (ele não falava em escopo da jurisdição) é a atuação da vontade concreta da lei; dava como característica da jurisdição, ainda, o caráter substitutivo em relação às atividades das partes envolvidas, que a ordem jurídica proíbe (autotutela).

Caracteriza-se a jurisdição, também, pela nota de extrema abertura no seu exercício, mediante a cooperação dos sujeitos interessados no resultado final. Essa participação é a essência do princípio do contraditório, assegurado constitucionalmente, seja para o processo penal, seja para o civil (embora o art. 153, § 16, da Constituição fale em contraditório na «instrução criminal», sabe-se que ela assim o faz em virtude de determinantes históricas: a nivel de teoria geral do processo, percebe-se com clareza que é o princípio em si mesmo que está ali acatado, sendo aplicável sempre que haja o exercício do poder com vistas a uma decisão imperativa ou constrição inevitável). Para o exercício assịm equilibrado e controlado da jurisdição é que se tem o concerto de princípios e garantias que se resumem na cláusula due process of law e que transparecem no binômio procedimento-contraditório. O processo é procedimento em contraditório e, para ser legitimo o seu resultado, precisa que em cada caso o procedimento seja adequadamente observado e a participação assegurada. O processo é um microcosmos democrático, miniatura do Estado orientado pela democracia (e ele é assim, em certa medida, mesmo quando o Estado abandona ou afrouxa os seus compromissos democráticos). Nesse concerto normas, princípios, garantias e instituições, é que ocupam lugar destacado a ação e a defesa. No processo civil, a ação constitui uma das garantias mais alcandoradas que o Estado concede ao valor liberdade e aos direitos individuais de toda ordem: a inafastabilidade da tutela jurisdicional é a chave da sobrevivência daquela e de todos estes, quando ameaçados ou violados. A defesa, como contraposto negativo da ação, é expressivo penhor da liberdade, especialmente no processo criminal, onde ela há de ser ampla (Const., art. 153, § 15) e é indispensável sob pena de invalidade.

\section{6 - O conteúdo da jurisdição}

É usual a preocupação de juristas e politicólogos, na determinação da missão específica e típica de cada um dos «Poderes do Estado». É impossivel falar em função típica do Judiciário, pois o que lhe cabe, entre as já lembradas funções instrumentais deste, são tarefas que também cs outros exercem. Reconhecidamente, é imperfeita e de valor relativo essa dita «separação de poderes». Sem considerar as atividades puramente administrativas do Poder Judiciário (auto-governo da Magistratura, regimentos internos dos tribunais, etc.) e permanecendo estritamente no campo de suas atividades jurisdicionais, vemos que estas são exercidas com dois endereçamentos, entre aquelas funções instrumentais: 
a) revelar imperativamente, em casos concretos, a vontade virtualmente contida nas normas gerais e abstratas integrantes do ordenamento jurídico. Isso os juízes fazem quando julgam; trata-se, portanto, de atividade integrada no conceito de conhecimento. Não só os juízes julgam, mas os administradores também; nem o ato de julgar é exclusivo da jurisdição, nem mesmo do Estado (todos julgamos a todo momento, em variadas situações, embora os nossos juízos não sejam dotados de imperatividade e muito menos autoridade de coisa julgada);

b) realizar os resultados práticos que correspondem à vontade do direito no caso concreto. Trata-se da execução, que será jurisdicional sempre que se tratar de dar efetividade a um direito insatisfeito, à custa do patrimônio do obrigado recalcitrante (mas também fora do âmbito da jurisdição se vê execução na realização de obras e serviços por conta da Administração Pública, que é o próprio Poder Executivo).

\section{7 - Cognição e execução}

Os povos sempre tiveram bastante cuidado com a execução, desde os albores da sua civilização. Entre os romanos, estava firmemente estabelecida a exigência de prévia cognição, a que se seguiria a actio judicati, observando-se o tempus judicati para ter-se a certeza do inadimplemento. Os germânicos prendiam-se à necessidade de ato voluntário do devedor, declarando aceitar a execução. O título executivo, produto do direito comum italiano (ano 1.000), é a síntese de pensamentos cautelosos com a liberdade do devedor e sua integridade corporal e patrimonial. Non est inchoandum ab executione, é regra de liberdade que prevalece absoluta no processo penal dos povos civilizados (inexiste-título executivo extrajudicial em matéria penal, donde nulla poena sine judicio). O processo de conhecimento é pressuposto da execução forçada também no civil, ou pelo menos pode ser instaurado para aferição da legitimidade de constrições ocorridas na execução (embargos do executado ou de terceiro) : no Estado-de-direito, são inadmissiveis as transgressões incontroladas e não-fundamentadas à liberdade e ao patrimônio das pessoas.

\section{8 - A liberdade através do processo de conhecimento}

Como pressuposto ou meio de controle dos atos de constrição judicial, em si mesmo o processo de conhecimento é instrumento da liberdade. Em matéria criminal, a própria rigorosa e constitucionalmente indispensável anteposição à execução forçada já é um penhor de garantia à liberdade individual. É nesse sentido que o prof. Canuto Mendes de Almeida afirma que o direito processual penal tem o objetivo de assegurar a liberdade do acusado.

Depois, o processo faz-se também sob o signo da liberdade. Seja no civil ou no penal, atuam as partes mediante atos voluntários, no sentido de que os realizam ou deixam de realizar, ou realizam-no mediante o conteúdo preferido, tudo de acordo com sua disposição, vonta- 
de, escolha, estratégia. A propositura da ação civil é deixada ao livre jogo de interesses. A oposição da defesa em qualquer processo, idem (sem que a inércia de uma das partes signifique inevitável sucumbência). Assim também a produção de provas ou interposição de recursos (Couture). Uma das maiores contribuições trazidas ao direito processual neste século foi a descoberta de que o processo é impulsionado muito mais por ônus das partes, do que por deveres a que supostamente ligadas (Goldschmidt) —, sendo da essência do ônus a liberdade em cumpri-los ou deixar de fazê-lo, com a consciência da conseqüência jurídica que virá.

Reduzindo a um quadro exemplificativo o significado do processo de conhecimento perante o valor liberdade, chegamos às seguintes proposições:

a) em princípio, não se executa sem prévia cognição (salvo a execução civil por título extrajudicial, controlada em sua justiça substancial por outro processo de conhecimento, que são os embargos). Trata-se de garantia oferecida ao acusado ou ao suposto devedor, contra os impulsos e açodamentos do acusador ou do credor;

b) o processo de conhecimento não se instaura sem as condições mínimas estabelecidas em lei. Trata-se dos pressupostos processuais e condições da ação, entre as quais figura a justa causa: sem o suficiente grau de plausibilidade, representado por esta (famus boni juris), carece de ação o Ministério Público ou o querelante, sendo rejeitada liminarmente a peça acusatória. Diferentemente do que acontece com o processo civil de conhecimento (talvez a diferença seja de grau), a mera pendência do processo criminal é por si mesma muito onerosa, portadora de um constrangimento que o direito só tolera se razoavelmente provável a acusação. $O$ processo crime instaurado sem justa causa é constrangimento ilegal, debelável pela via do habeas corpus;

c) o processo de conhecimento é instrumento para a realização futura de possíveis direitos (processo civil), seja pela condenação imposta ao réu, seja pela constituição de situações novas, seja mediante a mera declaração de existência ou inexistência de relação jurídica entre as partes. Hoje, a escalada para a ampla abertura do Judiciário é a resposta adequada do sistema jurídico (e jurídico-processual) às exigências políticas do Estado-de-direito, onde não devem ficar residuos de pretensões inacessiveis à Justiça. A batalha Juizado Especial das Pequenas Causas pela proteção jurisdicional ao meio ambiente no quadro da tutela aos interesses difusos - , eis dois exemplos ilustrativos dessa abertura, que só em clima de culto à liberdade e demais valores fundamentais da nação e do homem poderá ter efitividade;

d) a chamada «jurisdição constitucional das liberdades», da mesma forma, autoriza o acesso da pessoa à «ordem jurídica justa», agora na defesa específica de suas liberdades públicas em face de atos estatais inconvenientes. Na condição de demandante, quem afirma a 
existência de atos assim, ou mesmo desvio e abusos de poder (mandado de segurança, habeas corpus), será ouvido pelo Poder Judiciário;

e) o resultado do processo de conhecimento é legitimado pela observância de procedimentos preestabelecidos (cfr. Niklas Luhmann, Legitimação pelo procedimento). O produto acabado do processo de conhecimento é a sentença de mérito, que como todo provimento estatal (ato imperativo) há de ser gerado mediante a participação dos sujeitos que ficarão depois atingidos por sua eficácia direta (partes). Tal é a essência do princípio do contraditório, aplicável a processos de toda espécie (Const., art. 153, § 16: v. supra, n. 5) Essa é uma postura política que se projeta sobre o processo, para a liberdade das partes e mediante as exigências inerentes à cláusula due process of law (maculado o procedimento, com prejuízo para a participação, tem-se a invalidade do processo e do seu resultado). Esse aspecto da relevância do processo de conhecimento em face do valor liberdade não diz respeito ao réu ou ao autor, mas a ambos, pois o contraditório é precisamente a arma da dialética que no processo se desenvolve, mercê dos valores antagônicos que estão à base das pretensões das partes em oposição (no criminal, liberdade pessoal $\mathrm{x}$ interesse público).

\section{9 - Escopo específico do processo de conhecimento}

É velha em direito processual a polêmica em torno do escopo do processo, ou da jurisdição (e prefiro dizer: das instituições processuais e judiciárias e do próprio direito processual como um todo). Querendo superar a antinomia entre as colocações subjetivas e objetivas (Zanzucchi) e mesmo aquela marcadamente juridica de Chiovenda, os alemães modernos vão falando nos escopos de realizar o direito objetivo e tutelar direitos subjetivos(Habscheid), ou assim: "garantia jurídica e paz legal, uma ao lado da outra» Stein- Jonas-Schönke-Pohle). Não sendo uma estrutura fechada, mas aberta e dependente (Bobbio, Celso Lafer), o processo de conhecimento presta-se aos objetivos traçados para a jurisdição e para o direito processual (que é, resumidamente, a disciplina jurídica da jurisdição). Tem, contudo, dentro do sistema processual, o seu papel específico: o de conferir segurança às relações jurídicas. Juízo todos fazemos, julgar todos julgamos. Mas julgar com força imperativa é exercício do poder. Com resultado de um procedimento, os julgamentos estatais impõem-se e impõem a sua eficácia na vida das pessoas em relação. Depois, com a coisa julgada material, essa eficácia torna-se imutável e o processo de conhecimento, ao se extinguir, terá deixado no mundo essa marca indelável de sua realização. Também a coisa julgada é um valor protegido constitucionalmente (art. $\left.153, \S 3^{\circ}\right)$, porque a segurança nas relações jurídicas é em si mesma um valor a ser mantido na vida social.

\section{0 - Processo de conhecimento e certeza}

Ao longo da História, a busca da verdade tem sido incessante nas atividades do homem. Dizem até que todo procedimento visa a ela 
(Luhmann). E o movimento iluminista, com o repúdio ao obscurantismo, propôs a iluminação da justiça e da verdade, através da razão. O processo ganhou muito com isso, embora a obsessão pela verdade e a rigorosa exigência da certeza nos julgamentos (sob pena de ter-se por inexistente o fato) tenha sido sempre e seja ainda hoje pretexto para a burocracia e fonte de muitas injustiças: bem pensado, repudiar uma boa probabilidade é o mesmo que aceitar a versão menos provável, só pelo gosto de prestigiar as situações estabelecidas, não-obstante injustas, e reverenciar a máxima allegatio et non probatio quasi non allegatio. Ao romper a «tensão entre conhecimento e ignorância» (Karl Popper), o juiz chega à certeza quando pode, mas deve contentar-se com a probabilidade quando boa e suficiente para tornar menos sensata a insistência em julgar contra ela. Sendo a certeza a «manifestação subjetiva da verdade» Sentís Melendo), é também impossível traçar objetivamente a linha divisória entre ela e a probabilidade. Assim, o conhecimento desenvolvido pelo juiz no processo considera-se satisfatório no momento em que ele se satisfaz, ou seja, quando em seu espírito ele considera definitivamente afastados os «motivos divergentes», inclusive apoiando-se naquilo quod plerumque fit.

O ponto extremo da certeza (jurídica) a que se chega no processo é representado pela coisa julgada, que os antigos diziam que pro veritate habetur. Sabe-se, porém, que a res judicata não corresponde a essa pretendida ficção e «a verdade dos fatos, estabelecida como fundamento da sentença», não fica coberta pela autoridade do julgado: CPC, art. 469 , inc. II.

O próprio legislador, aliás, demonstra transigir com o ideal da verdade transparecendo na certeza elevada o grau absoluto: eis as praesumptiones legis, fixadas em casos nos quais ele é levado a aceitar a boa probabilidade e dar-lhe tratamento equiparado ou aproximado ao da certeza (presunção absoluta ou relativa, respectivamente).

\section{1 - Objeto do conhecimento}

O juiz conhece matéria de fato e de direito, no processo. Ex facto oritur jus e em toda causa existe invariavelmente alguma situação concreta da vida, (ou «segmento da História», a ser objeto de valoração à luz das normas abstratas contidas no ordenamento jurídico. Ainda quando o fundamento fático da demanda seja incontroverso e disponível o direito, o raciocínio do juiz caminhará sempre entre o fato alegado e o direito considerado do seu próprio ponto-de-vista (jura novit curia). Pontos incontroversos são os que não se erigiram em questões e permanecem como pontos mesmo, que o juiz levará em conta no seu julgamento. $\mathrm{O}$ julgamento, pois, inclui invariavelmente pontos de fato e de direito - , às vezes controvertidos e às vezes menos, mas sempre integrantes do processo lógico que ele desenvolverá.

Os pontos sobre que incide o conhecimento do juiz, no processo cognitivo, distribuem-se pelas pontas de um trinômio e referem-se ao 
mérito (ou seja, à pretensão deduzida em juízo), às condições da ação e aos requisitos de regularidade do processo mesmo (entre eles, os pressupostos processuais).

Tal é pois, o objeto do conhecimento do juiz no processo, que não se confunde com o próprio objeto do processo (Streitgegenstand, que alguns preferem designar por «objeto litigioso») : este é o mérito, ou seja, a pretensão deduzida pelo autor (e o mérito não se confunde com as questões de mérito, ou seja, com os pontos controvertidos referentes à pretensão deduzida). O juiz conhece ex officio de pontos às vezes não suscitados pelas partes, além de suscitar ele próprio controvérsias a propósito de pontos que as partes não questionam (as objegões, em oposição às exceções de mérito em sentido estrito: v. CPC, art. 128, parte final); o objeto do processo ele não pode alterar, nem pode ampliá-lo o réu (salvo reconvenção); mas o réu pode também ampliar o objeto do conhecimento do juiz, alegando fatos novos (art. 326) ou trazendo pontos novos de direito à discussão.

\section{2 - Conhecer}

$\mathrm{Na}$ busca da verdade e com vistas a formar sua convicção, o juiz abre-se à instrucão a ser feita segundo as formas que os modelos procedimentais predispõem. Instruir é preparar (e não constitui exclusividade do processo de conhecimento). No processo de conhecimento, instruir é preparar o espírito do juiz para julgar (especialmente, para julgar o mérito). As partes instruem e o próprio juiz se instrui.

$\mathrm{E}$ instrução não é sinônimo de prova, mas o gênero em que esta está contida como espécie (ou o contexto de atividades entre as quais a atividade probatória se situa). O espírito do juiz é preparado por toda e qualquer informação ou sugestão que lhe chegue, sendo apta a provocar-lhe intuições ou a confirmar hipóteses. Instrução inclui prova, quando há fatos duvidosos a esclarecer (questões de fato); e inclui também as alegacóes, com que os patronos das partes examinam o resultado da experiência probatória, propõem interpretação dos textos, confrontam fatos e normas, criticam-se reciprocamente.

$\mathrm{E}$ o juiz, em sua atividade cognitiva que só por comodidade e a posteriori se pode dizer encaixada nos parâmetros de um silogismo (sobre a "gênese lógica da sentença», Calamandrei), passa sua mente por um processo que inclui pelo menos quatro fases: a) interpretar o pedido, para chegar à essência daquilo que o demandante pretende (fala a lei em interpretação "retritiva», art. 293, mas o correto é entender-se que ela há de ser estrita: sem ampliações e sem restrições); b) levantar os pressupostos de diritto matrial, ou seja, os pressupostos de fato dos quais a lei faz depender a existência do direito que o autor alega ter; c) verificar as alegações de fato, para saber se a causa de pedir inclui os fatos que, segundo a lei material, têm o efeito pretendido pelo autor (porque, não sendo alegados fatos legitimamente relacionados com a pretensão formulada, a demanda é incongruente e 
a petição inicial será indeferida por inepta: art. 29a, par. ún., inc. II); d) indagar se estão comprovadas as alegacõos de fato. que esse iter lógico fique bastante simplificado na maioria dos casos, máxime quando o juiz tem familiaridade com a matéria em causa obrigatoriamente essa a ordem das observações que o juiz faz, porque o conhecimento inclui muito de intuição e grande dose de subjetivismo e métodos pessoais. Como mero traçado dos pontos pelos quais o conhecimento em princípio passa, é significativo e fiel essa acima descrito (idéias a partir de Rosenberg). E o conhecimento, com essas características mais ou menos definidas, há de ser visto «como uma importante técnica de adequação do processo à natureza do direito ou à peculiaridade da pretensão a ser tutelada» Watanabe).

\section{3 - Conhecimento no processo de execugão}

O escopo específico da execução civil é muito diferente do de segurança jurídica, que caracteriza a cognição. Quer-se, agora, a satisfação dos direitos subjetivos, ou da «vontade concreta da lei» (Chiovenda), ou (melhor ainda): a realização prática do preceito jurídico-substancial aplicado ao caso concreto. Por isso mesmo é que se diz execuģão, empregando vocábulo que dá a idéia de perseguição do bem devido segundo o direito (ex + sequor). Não são atividades que se desenvolvam para conhecer e portanto julgar, mas para aplicar à realidade concreta a sanção executiva (Liebman), a que é um resultado prático.

Isso não significa, porém, que inexista conhecimento no processo de execução. Não ser um conjunto de atos ordenados com vistas ao conhecimento como resultado não importa em ser uma atividade cega de qualquer tomada de contato com a verdade e priva de toda $\mathrm{e}$ qualquer determinação de rumos a seguir. Há seguidas decisões interlocutórias no processo executivo, as quais se caracterizam como soluções dadas a questões incidentes $\left(\mathrm{CPC}\right.$, art. $162, \S 2^{\circ}$ ) relativas ao processo mesmo e às condições da ação Martinetto). Em suma, o leque do trinômio descrito com relação ao processo de conhecimento fica reduzido aqui a um binômio, porque as questões atinentes ao mérito (ou seja, à existência ou inexistência do direito do exeqüente) ficam deslocadas para a sede dos eventuais embargos do executado.

\section{4 - Conhecimento no processo cautelar}

Também sem ser um processo «de conhecimento», o cautelar envolve certa medida de busca da verdade, ou seja, certa dose de instrução voltada ao conhecimento. Tratando-se de medidas instrumentalmente preordenadas a um processo ou medida principal (instrumentalidade hipotética: Calamandrei), é natural que as cautelares não fiquem cobertas pela autoridade da coisa julgada. «Entre fazer logo porém mal, e fazer bem embora tarde, os provimentos cautelares visam acima de tudo a fazer logo, deixando que o problema do bem e 
do mal, isto é, da justiça intrínseca do julgamento, seja resolvido mais tarde, com a necessária ponderação, nas formas sossegadas do processo ordinário.» A menor fixidez das medidas cautelares, que se destinam a resolver com urgência situações de urgência e podem ser a qualquer tempo revogadas, sem as peias da coisa julgada (CPC, art. 807), justifica a cognição bem mais superficial que é feita na sua preparação. Basta demonstrar a plausibilidade da situação alegada, ou seja, o fumus boni juris, que é expressão de uma probabilidade suficiente. Daí falar-se em «intrução sumária».

\section{5 - Conhecimento, publicidade, motivação, justiça e liberdade}

A onipresença do conhecimento, que faz do juiz perene fiscal dos seus próprios atos antes de praticá-los e impor imperativamente suas decisões e constrições, é o penhor maior da liberdade e da justiça, que o Estado-de-direito oferece aos litigantes. Nem é à-toa que o sistema exige a publicidade dos atos do processo, como garantia política de primeira linha e sólidas raízes históricas (Robespierre: «donnez-moi le juge que vou voudrez: partial, corrupt, mon ennemi même, si vous voulez, peu m'import parvu qu'il ne puisse rien faire qu'a la face du public»), impondo ao juiz o dever de fundamentar as decisões de mérito a que o seu livre convencimento o tiver conduzido (CPC, art. 131): nos «motivos» da sentença, está a humildade imposta a quem não decide arbitrariamente segundo critérios próprios, mas decide segundo a lei e os fatos provados, após inteirar-se destes e capacitar-se do significado substancial daquela, tudo nessa atividade que é o conhecimento. Em regime de legalidade, não se aceitaria julgar sem antes bem conhecer...

... porque, como diria Canuto Mendes de Almeida, «primeiro é preciso julgar, para depois condenar».

\section{Bibliografia}

(autores referidos e suas obras)

ARAứo CINTRA, Antonio Carlos de - Teoria geral do processo, ne ed., S. Paulo, Ed. Rev. Trib., 1986 (em coop.).

BOBBIO, Norberto - «Teoria sociologica e teoria generale del diritto», in La sociologia del diritto: un dibattito, Mileão, Giuffrè, 1974.

CALAMANDREI, Piero - Introduzione allo studio sistematico dei provvedimenti cautelari, Pádua, Cedam, 1936.

- Istituzioni di diritto processuale civile, Pádua, Cedam, 1943.

ChIOvenda, Giuseppe - Principii di diritto processuale civile, $4^{4}$ ed., Nápoles, Jovene, 1928.

COUTURE, Eduardo Juan - o princípio da liberdade no sistema do processo civil, Lisboa, Ed. Jornal do foro, 1948.

DALLARI, Dalmo de Abreu - Elementos de teoria geral do Estado, 2 a ed., S. Paulo, Saraiva, 1973. 
DINAMARco, Candido Rangel - Teoria geral do processo, 64 ed., S. Paulo, Ed. Rev. Trib., 1986 (em coop.).

- Execucão civil, S. Paulo, Ed. Rev. Trib., 1973 (24 ed. no prelo).

FERREIRA FILHO, Manoel Gonçalves - Curso de direito constitucional, S. Paulo, Saraiva, 1975.

- «Conjuntura politica nacional - o Poder Executivo», Rio, ESG, 1974.

GOLDSCHMIDT, James - Principios generales del proceso, Buenos Aires, Ejea, 1961.

GRINOVER, Ada Pellegrini - Teoria geral do processo, ne ed., A. Paulo, Ed. Rev. Trib., 1986 (em coop.).

HABSCHEID, Walther J. - «As bases do direito processual civil», in Rev. proc., v. 11-12 (trad. Arruda Alvim).

LAFer, Celso - O Brasil e a crise mundial, S. Paulo, Perspectiva, 1984.

LUHMANN, Niklas - Legitimação pelo procedimento, Brasflia, UnB, 1980 (trad. M.C. Corte Real).

MARTINETTO, Giuseppe - Gli accertamenti degli organi esecutivi, Milåo, Gluffrè, 1963.

MENDES DE ALMEIDA, Joaquim Canuto - A contrariedade na ingtrucão criminal, $\mathbf{S}$. Paulo, 1937.

POPPER, Karl - Lógica das clências sociais, Rlo-Bras., Tempo bras.-UnB, 1978.

ROSENBERG, Leo - Die Baweislast (trad. argentina: «La carga de la prueba», Buenos Aires, Ejea, 1956).

SENTfS MELENDO, Santiago - La prueba - los grandes temas del derecho probatorio, Buenos Aires, Ejea, 1978.

WATANABE, Kazuo - Contribuicão ao estudo da cognigão no processo civil, tese, USP, 1985 (inédita).

ZANZUCCHI, Marco Tullio - Diritto processuale civile, 4* ed.. Milăo, Giuffrè, 1964 